\title{
Review Article \\ Diagnostically Relevant Molecular Markers in Head and Neck Neoplasms
}

\author{
Soma Susan Varghese, ${ }^{1}$ Philips Mathew, ${ }^{2}$ and Jithin Jose ${ }^{3}$ \\ ${ }^{1}$ Department of Oral Pathology and Microbiology, Mar Baselious Dental College and Hospital, Kothamangalam, Kerala, India \\ ${ }^{2}$ Department of Oral Medicine and Radiology, Rajah Muthiah Dental College and Hospital, Annamalai University, \\ Chidambaram, Tamil Nadu, India \\ ${ }^{3}$ Department of Oral Pathology and Microbiology, Indiragandhi Dental College, Kothamangalam, Kerala, India
}

Correspondence should be addressed to Soma Susan Varghese; drsomasusan@yahoo.in

Received 15 March 2013; Accepted 16 May 2013

Academic Editors: R. Smith and Z. Wang

Copyright (C) 2013 Soma Susan Varghese et al. This is an open access article distributed under the Creative Commons Attribution License, which permits unrestricted use, distribution, and reproduction in any medium, provided the original work is properly cited.

Tumor markers are grouped into diagnostic and prognostic markers. Specific diagnostic markers appear extensively in cells of a particular neoplasm and not in other tumors. These markers can be used to assess the cellular lineage and histogenic origin of various neoplasms. Thus, diagnostic markers can be used for the confirmatory diagnosis of various tumors. This paper reviews the literature on various diagnostic markers and aims to group them based on the cellular lineage of neoplasms.

\section{Introduction}

Tumor markers are proteins produced by the tumor cells or by other cells of the body in response to cancer or certain benign (noncancerous) conditions. These substances can be found in the blood, in the urine, in the tumor tissue, or in other tissues. Different tumor markers are found in different types of cancer, and levels of the same tumor marker can be altered in more than one type of cancer [1].

Tumor markers can be categorized into diagnostic and prognostic markers. Antigens or clusters of antigens expressed by the tumors can be detected with the help of specific diagnostic investigations [1]. Based on the expression, the diagnostic markers can be classified into mesenchymal marker, epithelial markers, markers for muscle differentiation and neural differentiation, vascular markers, and markers for melanin, histiocytes, and leukocytes. Even the most perplexing round cell tumors, spindle cell tumors, and carcinosarcoma can be distinguished with the help of specific diagnostic markers. Prognostic markers can determine the growth, metastasis, and invasion potential of tumor. Common methods used to identify tumour-related protein include immunohistochemistry, fluorescent in situ hybridization (FISH), and reverse transcriptase-polymerase chain reaction.
Immunohistochemistry is one of the methods wherein the antibody-based reagent is used for the localization of specific epitopes in tissue sections to detect the histogenic origin of the tumor. RT-PCR enzymatic reaction with reversed transcriptase can be used to assess gene expression and micrometastasis in tumour [2].

\section{Diagnostic Markers for Tumors with Muscle Cell Differentiation}

2.1. Desmin. Desmin is a type III intermediate filament found near the $\mathrm{Z}$ line in sarcomeres. It is a $52 \mathrm{kD}$ protein that is a subunit of intermediate filaments in skeletal muscle tissue, smooth muscle tissue, and cardiac muscle tissue. Its presence in vascular smooth muscle is variable [3]. The muscle cell matures only if desmin is present. Vimentin is present in higher amounts during embryogenesis while desmin is present in higher amounts after differentiation. This suggests that there may be some interaction between the two in determining muscle cell differentiation [3].

Desmin is detected in rhabdomyosarcoma of all subtypes, benign smooth muscle tumours, benign skeletal muscle tumours and leiomyosarcoma (50\%) [4]. Desmin shows slight immunoreactivity to various spindle cell lesions which are 
not traditionally considered of smooth muscle origin, which has been interpreted as evidence of focal myofibroblastic differentiation in tumours like fibromatosis, angiomatoid malignant fibrous histiocytoma, and myofibroblastoma [5]. Neuroectodermal tumours, Ewing's sarcoma, fibrosarcoma, neuroblastoma, and mesothelial cell tumours show expression of desmin occasionally $[6,7]$.

2.2. Actin. Actins are family of contractile proteins of molecular weight $(42 \mathrm{kd})$ which are divided into alpha, beta, and gamma subtypes depending on electrophoretic mobility. There are three isoforms of alpha actin (alpha-skeletal, alphacardiac, and alpha-smooth muscle) and two forms of gammaactin (gamma-smooth muscle and gamma-cytoplasmic). $\alpha$ Actin is normally restricted to smooth muscle cells [8].

Actin is also expressed in normal tissues like skeletal muscle, cardiac muscle, pericytes, smooth muscle, myofibroblast and myoepithelial cells. Antibodies directed against alpha smooth muscle actin show positivity for smooth muscle cells and myofibroblasts, but not cardiac and skeletal muscle. Actin plays an important role in carcinogenesis. The cell transformation is accompanied by a loss of actin filaments. Alterations of actin polymerization or actin remodeling played a pivotal role in regulating the morphologic and phenotypic events of a malignant cell [9].

The actin antibody (HHF-35) can be used for immunostaining of myofibroblastic cells within granulation tissue, scar tissue, nodular fasciitis, and fibromatosis. Muscle specific actin antibody can express rhabdomyosarcoma, and the intensity of staining depends on the differentiation of the tumour [10]. Most of the leiomyosarcomas express muscle specific actin. Nodular fascitis and rhabdomyoma also show the expression of muscle specific actin. Bello et al. analyzed the expression of $\alpha$-smooth muscle actin in ameloblastic carcinoma and found positive expression of smooth muscle actin in the stroma and concluded that smooth muscle actin could play an important role in tumour progression [11].

2.3. MyoD1. MyoD1 is a protein with a key role in regulating muscle differentiation. MyoD1 is expressed in activated satellite cells and myoblast. Myogenin is a member of a family of myogenic regulatory genes, which includes MyoD1 and MRF4. These genes encode a set of transcription factors, which are essential for muscle development. MyoD1 is involved in skeletal muscle differentiation. It is therefore a useful marker for tumors of the muscle lineage, being strongly expressed in alveolar rhabdomyosarcomas [12].

2.4. Myoglobulin. Myoglobulin is found in cardiac and skeletal muscles. This protein appears in early muscle differentiation but is not found in sufficient amount in tumours. Myoglobulin was found to be expressed only in $50 \%$ of the rhabdomyosarcomas [13].

\section{Diagnostic Markers for Tumours with Neural Differentiation}

3.1. S100. The protein is called "S100" because the constituents were soluble in $100 \%$ saturated ammonium sulphate neutral Ph. Schwann cells, glial cells, skeletal muscle, chondrocytes, lipocytes, macrophage subsets, and myoepithelial cells express S-100 normally $[14,15]$.

S100 protein is widely distributed in central and peripheral nervous systems. S100 protein is readily demonstrable in astrocytes, oligodendrocytes, schwann cells, folliculostellate cells of adenohypophysis, satellite cells of adrenal medulla, chondrocytes, adipocytes, myoepithelial cells, and various histiocytes which include Langerhans cells of epidermis and interdigitating reticulum cells of the lymph nodes. It is not present in perineurial cells [16]. S100 is positive in neurilemomas and neurofibromas, although the intensity and percentage of positive cells are far less in neurofibromas than in neurilemomas. This suggests that neurilemomas are composed of uniform population of schwann cells, whereas neurofibromas contain an admixture of fibroblast and perineural cells. S100 protein staining is invaluable in the diagnosis of cellular schwannoma, which is often mistaken for fibrosarcoma or malignant peripheral nerve sheath tumour. Within cellular schwannoma, S100 protein is consistently diffuse and intense in contrast to the focal or weak staining in malignant schwann cell tumours. S100 protein can be identified in granular cell tumours also providing additional evidence for their neural origin. Unlike benign nerve sheath tumour, only about half of the malignant nerve sheath tumours express the protein, and in this case staining tends to be focal and spotty. Nearly all melanomas regardless of the degree of pigmentation express S100 protein [17]. Certain carcinomas also may express S100 proteins (lungs and breast). S100 protein is present within occasional nonneural tissues and tumours. Both normal Langerhans cells and the cells of histiocytosis X strongly express S100. Unlike many other antigens, valid staining for S100 protein can be seen in nucleus or cytoplasm or both. Paragangliomas, neuroblastoma, rabdomyoma, myositis ossificans progressive, and granular cell tumour shows variable expression of S100. Nerve sheath myxoma shows strong expression of S100 protein [17].

In mixed tumour of salivary gland myoepithelial cells demonstrate S100 proteins [18]. The epithelial cells of canalicular adenoma show S100 positivity [19]. Acinic cell adenocarcinoma shows occasional positivity for S100 protein. Ductal cells of adenoid cystic carcinoma show positivity for S100 protein [20]. In epithelial myoepithelial carcinoma, the neoplastic cells show nuclear and cytoplasmic staining for S100. Polymorphous low grade adenocarcinoma and undifferentiated carcinoma show varying degree of expression of S100 protein [21]. Desmoplastic ameloblastoma and odontogenic myxoma show a variable expression of S100 protein [22].

3.2. Glial Fibrillary Acidic Protein. GFAP is an intermediate filament protein of glial cells. It can be used to distinguish glial hamartomas of soft tissue from nonglail lesions. GFAP is a constituent of glial cells of the astrocytic lineage and is also present in primary glial brain tumors. Neurilemomas show occasional expression of GFAP. Neuroblastoma also shows positivity for this marker [23]. Mixed tumours of salivary gland are variably positive for GFAP. 
3.3. Neuron Specific Enolase. Enolase is an enzyme involved in glycolytic pathway. It exists as three immunological subunits (alpha, beta, and gamma). Beta-beta is found in skeletal muscle, alpha-alpha in glial cells of brain, and gamma-gamma and gamma-alpha in neurons. The gamma subunit can be identified in neuronal and neuroendocrine cells, although the intensity of the immunoreactivity varies with the type of cells. It can also be identified in neuronal and neuroendocrine cells and is also identified in plasma cells and megakaryocytes. Fifty percent of neuroblastomas, paragangliomas, and neuroendocrine tumours express neuron specific enolase. About one-third of the malignant melanomas also produce the enzyme [24].

3.4. Neurofilament Protein, Myelin Basic Protein, Leu-7, and Nerve Growth Receptor Proteins. Neurofilament protein has been identified within neuroblastomas, ganglioneuroma, and paraganglioma. The amount of staining is proportional to the amount of cytoplasm [25]. Mylein basic protein is a basic polypeptide present in myelin sheath. It can be identified in benign and malignant schwann cell tumour and granular cell tumours. This protein can be used to distinguish malignant schwannoma from malignant melanoma [26]. Leu-7 is an antigenic marker for lymphocytes with natural killer activity. It is also identified within benign and malignant nerve sheath tumours as well as neuroendocrine tumours [27]. Synaptophysin is a membrane protein found in presynaptic vesicles of nerve cells. It can be identified within the nerve cells of the peripheral and CNS as well as neuroendocrine cells. This protein is expressed in neuroendocrine tumours, neuroblastomas, ganglioneuroblastoma, ganglioneuroma, and paraganlioma [28]. Nerve growth receptors can be identified in many benign and malignant nerve sheath tumours and neuroblastic tumours. This protein can be detected in granular cell tumour, neurofibromas, and schwannomas [28].

\section{Diagnostic Markers for Tumours with Vascular Cell Differentiation}

4.1. Factor-VIII-Associated Antigen (von Willebrand Factor). Factor VIII is a complex of two components that have different biochemical, functional, and immunological properties. Factor-VIII-associated antigen (Von Willebrand factor) is synthesized by endothelial cell. It is also found in platelets and megakaryocyte. It is considered as a good marker for endothelial differentiation. This antigen can be demonstrated in normal endothelium and endocardium and in most of the benign vascular tumours (hemangiomas, pyogenic granuloma) [29]. Low grade vascular tumours like epithelioid hemangioendothelioma and spindle cell hemangioendothelioma express factor-VIII-associated antigen. The expression of factor-VIII-associated antigen is very low in angiosarcoma. Although Kaposi sarcoma is regarded as a vascular tumour, it does not appear to express factor-VIII-associated antigen. Lymphangioma shows variable expression of factorVIII-associated antigen. Capillary hemangiomas, Cavernous hemangiomas, Epitheloid hemangiomas, Synovial hemangiomas and Hemangiomas of peripheral nerve show the expression of factor-VIII-associated antigen. Ideally, factorVIIIassociated antigen immunostaining should be intense, granular, and confined to the cytoplasm [29].

4.2. CD-34. The CD-34 antigen is expressed on hematopoietic progenitor cells of lymphoid and myeloid linage in the bone marrow and in some acute leukemias. It is also expressed in vascular endothelial cells and dentritic cells. It is detected in most of the benign vascular tumours. About 80 $90 \%$ of malignant tumours including Kaposi'sarcoma contain this antigen [30]. CD-34 expression is also well documented in fibrohistiocytoma, dermatofibrosarcoma, solitary fibrous tumour, malignant peripheral nerve sheath tumour, and epitheloid sarcoma [31].

4.3. CD-31 (Platelet-Endothelial Cell Adhesion Molecule). $\mathrm{CD}-31$ antigen is a transmembrane glycoprotein expressed by endothelial cells as well as various hematopoietic cells, including megakaryocytic, plasma cells, and platelets. All benign vascular tumours express this antigen and in addition about $80-100 \%$ of angiosarcomas have identifiable immunoreactivity [32]. Rarely, malignant mesothelioma, leiomyosarcoma, and occasionally carcinoma possess this antigen. Lymphangioma also shows a variable expression for this antigen.

\section{Histiocytic Markers}

Enzymes alpha-1 antitrypsin, alpha-1 antichymotrypsin, and muramidase (lysozyme) are the three most common substances utilized in the diagnosis of histiocytic and presumed histiocytic lesion.

5.1. CD-68. CD-68 is a constituent of lysosomes. Among the neoplasms, it is expressed in some histiocytic, myeloid, and myelomonocytic malignant tumours and is also present in lymphomas of B-cell lineage. It is also expressed in certain carcinomas and granular cell tumours which are characterized by a superabundance of larger phagolysosomes. It is used to detect malignant fibrous histiocytoma and presents in half of the angiomatoid fibrous histiocytoma [33].

\section{Diagnostic Marker for Mesenchymal Tumors}

6.1. Vimentin. Vimentin is the intermediate filament traditionally associated with mesenchymal cells and mesenchymal tumours which is present in a wide variety of cells during early embryological development and is replaced by a type of specific intermediate filament in the course of differentiation. Vimentin is the major IF protein in mesenchymal cells, and it is frequently used as developmental marker of cells and tissues. Vimentin is normally expressed in fibroblast, chondroblast, smooth muscle cells, mesothelium, pericytes, melanocytes, and endothelial cells [34]. Vimentin is expressed in most of the sarcomas. Several reports have suggested that it can be identified in a variable percentage of normal epithelium and their neoplastic counterparts, especially if alcohol fixed material is used. Small percentages of squamous cell carcinomas express this antigen. 
In nodular fascitis and fibrosarcoma, spindle cells show the expression of vimentin [35]. Spindle cell lipoma and Epithelioid leiomyosarcoma show a variable expression of vimentin $[36,37]$. Among salivary gland neoplasms, mucoepidermoid carcinoma shows a variable expression of vimentin. In mixed tumour myoepithelial cells express vimentin. The mesenchymal part of carcinosarcoma expresses vimentin. Among odontogenic tumours solid multicystic ameloblastoma shows the expression of vimentin [38]. In adenomatoid odontogenic tumour there is immunoreactivity for vimentin in the ductal, tubular, and whorled structures. The spindle cells of odontogenic Myxoma show expression of vimentin [39]. Ameloblasticafibro-odontoma and complex odontome also showed the expression of vimentin [40].

\section{Diagnostic Marker for Epithelial Tumours}

7.1. Cytokeratin. Cytokeratins (CK) make up the largest subgroup of IF proteins and represent the most abundant proteins in epithelial cells. Their expression is site specific and differentiation dependent. At present, more than $60 \mathrm{CK}$ genes have been identified from the human genome sequence. Out of them fifty-four are functional genes. CK are subgrouped into Type I (acidic) of 40-56.5 kDa and Type II (basic) of 53$67 \mathrm{kDa}$. Type I and Type II cytokeratins are varied in their immuoreactivities and charge [41].

Depending on their tissue expression pattern, cytokeratins are grouped into simple epithelia specific cytokeratins $(7,8,18,19$, and 20$)$, stratified epithelia specific cytokeratins $(4,5,13,14,1,6,10$, and 19), keratinized stratified squamous epithelium cytokeratins $(5,14,1,6,10$, and 16$)$, non keratinized epithelium having cytokeratins $(4,13,19,5$, and 14$)$, squamous epithelial cytokeratins $(2,56$, and 10$)$ and odontogenic epithelium expressing cytokeratins 8 and 19 [42, 43].

It is also a valuable adjunct in the diagnosis of spindle cell tumours of the skin fibroxanthoma, spindle cell carcinoma and malignant melanoma. Paranuclear distribution of Keratin in Merkel cell carcinoma may be helpful in distinguishing this lesion from round cell sarcomas and lymphomas.

Cytokeratin has been expressed in leiomyosarcoma and Ewing's sarcoma. It is sporadically seen in malignant fibrohistiocytoma, liposarcoma, rhabdomyosarcoma, MPNST, hemangioendotheliomas, hemangiopericytoma, and angiosarcomas [41].

In mixed tumour of salivary gland, ductal epithelial cells and solid cellular nests with tubular structure strongly express cytokeratin [42]. Among odontogenic tumours solid multicystic ameloblastoma shows the expression of cytokeratin [44]. In desmoplastic ameloblastoma, cytokeratin expression is inconstant and confined to tumour cells with squamous differentiation [45]. Squamous odontogenic tumour expresses cytokeratins 16 and 13 in squamous cell [46]. In adenomatoid odontogenic tumour, there is immunoreactivity of cytokeratin in the ductal, tubular, and whorled structures [47]. Ameloblastic fibroodontoma expresses cytokeratins 8, 13, 16, 14,18 , and 19 in the epithelial component [40]. In calcifying ghost cell odontogenic tumour, nonghost cells show obvious immunoreactivity for cytokeratins, whereas ghost cells showed only faint or no positivity for cytokeratins [48].
TABle 1: Proposed classification of diagnostic markers.

\begin{tabular}{|c|c|}
\hline \multirow{5}{*}{$\begin{array}{l}\text { Markers for tumors with } \\
\text { muscle differentiation }\end{array}$} & Muscle specific actin \\
\hline & Desmin \\
\hline & Myogenin \\
\hline & Myoglobin \\
\hline & MyoD1 \\
\hline \multirow{8}{*}{$\begin{array}{l}\text { Markers for tumors with } \\
\text { neural differentiation }\end{array}$} & S100 \\
\hline & CD57 \\
\hline & P75NTR \\
\hline & Neurofilament \\
\hline & GFAP \\
\hline & Neuron specific enolase \\
\hline & Leu-7 \\
\hline & Myelin basic protein \\
\hline \multirow{5}{*}{$\begin{array}{l}\text { Markers for tumors with } \\
\text { Vascular cell differentiation }\end{array}$} & Von Willibrand-Factor \\
\hline & $\mathrm{CD}-34$ \\
\hline & CD-31 \\
\hline & Type 1V collagen \\
\hline & Ulex europaeus \\
\hline Markers for histiocytes & $\mathrm{CD}-68$ \\
\hline $\begin{array}{l}\text { Marker for mesenchymal } \\
\text { tumors }\end{array}$ & Vimentin \\
\hline \multirow{5}{*}{$\begin{array}{l}\text { Marker for epithelial } \\
\text { tumors }\end{array}$} & Cytokeratin \\
\hline & Integrin \\
\hline & Filaggrin \\
\hline & Involucrin \\
\hline & Desmosomal proteins \\
\hline \multirow{4}{*}{ Markers for melanin } & $\mathrm{S} 1 \mathrm{OO}$ \\
\hline & HMB-45 \\
\hline & Melanin A \\
\hline & Microphthalmia factor \\
\hline \multirow{4}{*}{ Markers for chondrocytes } & Leu-6 \\
\hline & Leu-7 \\
\hline & Leu-8 \\
\hline & S100 \\
\hline \multirow{13}{*}{ Markers for bone } & Alkaline Phosphatase \\
\hline & Type 1 collagen \\
\hline & Type 5 collagen \\
\hline & BMP-2 \\
\hline & BMP-7 \\
\hline & TG F $\beta$ \\
\hline & PDGF \\
\hline & IGF \\
\hline & Bone sialoprotein \\
\hline & Osteopontin \\
\hline & Osteocalcin \\
\hline & Osterix \\
\hline & Receptor activated nuclear factor \\
\hline
\end{tabular}




\section{Conclusion}

The diagnostic markers discussed can be summarized by classifying them as shown in Table 1. Diagnostic tumor markers help to evaluate the histogenesis and cellular lineage of various tumors. The methods commonly used to analyze the tumour antigens are immunohistochemistry, cytogenetics, fluorescent in situ hybridisation (FISH), and reversed transcriptase and polymerase chain reaction. Diagnostic markers can be used for the confirmatory diagnosis of various tumors.

\section{References}

[1] T. J. Pelkey, H. F. Frierson, and D. E. Bruns, "Molecular and immunologicaldetection of circulating tumor cells and micrometastases from solidtumors," Clinical Chemistry, vol. 42, pp. 1369-1381, 1996.

[2] G. V. Raj, J. G. Moreno, and L. G. Gomella, "Utilization of polymerase chainreaction technology in the detection of solid tumors," Cancer, vol. 82, pp. 1419-1442, 1998.

[3] M. L. Costa, R. Escaleira, A. Cataldo, F. Oliveira, and C. S. Mermelstein, "Desmin: molecular interactions and putative functions of the muscle intermediate filament protein," Brazilian Journal of Medical and Biological Research, vol. 37, no. 12, pp. 1819-1830, 2004.

[4] D. M. Parham, B. Webber, H. Holt, W. K. Williams, and H. Maurer, "Immunohistochemical study of childhood rhabdomyosarcomas and related neoplasms: results of an Intergroup Rhabdomyosarcoma Study project," Cancer, vol. 67, no. 12, pp. 3072-3080, 1991.

[5] A. K. Breuks and M. J. Trotter, "Expression of desmin and smooth muscle myosin heavy chain in dermato fibromatosis," Archives of Pathology \& Laboratory Medicine, vol. 126, p. 1179, 2002.

[6] A. L. Folpe, J. R. Goldblum, B. P. Rubin et al., "Morphologic and immunophenotypic diversity in Ewing family tumors: a study of 66 genetically confirmed cases," American Journal of Surgical Pathology, vol. 29, no. 8, pp. 1025-1033, 2005.

[7] D. M. Parham, P. Dias, D. R. Kelly, J. C. Rutledge, and P. Houghton, "Desmin positivity in primitive neuroectodermal tumors of childhood," American Journal of Surgical Pathology, vol. 16, no. 5, pp. 483-492, 1992.

[8] W. Ruan and M. Lai, "Actin, a reliable marker of internal control?” Clinica Chimica Acta, vol. 385, no. 1-2, pp. 1-5, 2007.

[9] T. Tsukada, D. Tippens, and D. Gordon, "HHF35, a muscleactin-specific monoclonal antibody. I. Immunocytochemial and biochemical characterization," American Journal of Pathology, vol. 126, no. 1, pp. 51-60, 1987.

[10] E. A. Montgomery and J. M. Meis, "Nodular fescitis, its morphogenic spectrum and immunohistochemicl profile," American Journal of Surgical Pathology, vol. 15, p. 942, 1991.

[11] I. O. Bello, K. Alanen, P. J. Slootweg, and T. Salo, "Alpha-smooth muscle actin within epithelial islands is predictive of ameloblastic carcinoma," Oral Oncology, vol. 45, no. 9, pp. 760-765, 2009.

[12] J. Rosai, P. Dias, D. M. Parham, D. N. Shapiro, and P. Houghton, "MyoD1 protein expression in alveolar soft part sarcoma as confirmatory evidence of its skeletal muscle nature," American Journal of Surgical Pathology, vol. 15, no. 10, pp. 974-981, 1991.

[13] J. J. Brooks, "Immunohistochemistry of soft tissue tumors. Myoglobin as a tumor marker for rhabdomyosarcoma," Cancer, vol. 50, no. 9, pp. 1757-1763, 1982.
[14] B. W. Moore, "A soluble protein characteristic of the nervous system," Biochemical and Biophysical Research Communications, vol. 19, pp. 739-744, 1965.

[15] D. B. Zimmer, E. H. Cornwall, A. Landar, and W. Song, "The S100 protein family: history, function, and expression," Brain Research Bulletin, vol. 37, no. 4, pp. 417-429, 1995.

[16] M. J. Vanstapel, K. C. Gatter, and C. De Wolf-Peeters, "New sites of human S-100 immunoreactivity detected with monoclonal antibodies," American Journal of Clinical Pathology, vol. 85, no. 2, pp. 160-168, 1986.

[17] S. W. Weiss and B. J. Nickoloff, "CD 34 is expressed by a distinctive cell population in peripheral nerve, nerve sheath tumours and related lesions," American Journal of Clinical Pathology, vol. 87, p. 425, 1987.

[18] J. J. Sciubba and R. B. Brannon, "Myoepithelioma of salivary glands: report of 23 cases," Cancer, vol. 49, no. 3, pp. 562-572, 1982.

[19] R. J. Zarbo, J. A. Regezi, and J. G. Batsakis, "S-100 protein in salivary gland tumors: an immunohistochemical study of 129 cases," Head \& Neck Surgery, vol. 8, no. 4, pp. 268-275, 1986.

[20] K. Hara, M. Ito, and J. Takeuchi, "Distribution of S-100b protein in normal salivary glands and salivary gland tumors," Virchows Archiv A, vol. 401, no. 2, pp. 232-249, 1983.

[21] C. Anderson, D. Krutchkoff, C. Pedersen, R. Cartun, and M. Berman, "Polymorphous low grade adenocarcinoma of minor salivary gland: a clinicopathologic and comparative immunohistochemical study," Modern Pathology, vol. 3, no. 1, pp. 76-82, 1990.

[22] C. H. Siar and K. H. Ng, "Patterns of expression of intermediate filaments and S-100 protein in desmoplastic ameloblastoma," The Journal of Nihon University School of Dentistry, vol. 35, no. 2, pp. 104-108, 1993.

[23] E. Kawahara, Y. Oda, A. Ooi, S. Katsuda, I. Nakanishi, and S. Umeda, "Expression of glial fibrillary acidic protein (GFAP) in peripheral nerve sheath tumors. A comparative study of immunoreactivity of GFAP, vimentin, S-100 protein, and neurofilament in 38 Schwannomas and 18 neurofibromas," American Journal of Surgical Pathology, vol. 12, no. 2, pp. 115-120, 1988.

[24] B. Seshi, L. True, D. Carter, and J. Rosai, "Immunohistochemical characterization of a set of monoclonal antibodies to human neuron-sepcific enolase," American Journal of Pathology, vol. 131, no. 2, pp. 258-269, 1988.

[25] M. Mukai, C. Torikata, and H. Iri, "Expression of neurofilament triplet proteins in human neural tumors," American Journal of Pathology, vol. 122, no. 1, pp. 28-35, 1986.

[26] M. Nadji and A. R. Morales, Immunoperoxidae Technique: A Practical Approach in Tumour Diagnosis, American Society of Clinical Pathlogist Press, Chicago, Ill, USA, 1986.

[27] E. Perentes and L. J. Rubinstein, "Recent applications of immunoperoxidase histochemistry in human neuro-oncology," Archives of Pathology and Laboratory Medicine, vol. 111, no. 9, pp. 796-812, 1987.

[28] V. E. Gould, B. Wiedenmann, I. Lee et al., "Synaptophysin expression in neuroendocrine neoplasms as determined by immunocytochemistry," American Journal of Pathology, vol. 126, no. 2, pp. 243-257, 1987.

[29] M. Schested and K. Hou-Jenson, "Factor V111 related ANTIGEN as an endothelial cell marker in bening and malignant diseases," Virchows Archiv, vol. 391, p. 217, 1981.

[30] B. J. Nickoloff, "The human progenitor cell antigen (CD34) is localized on endothelial cells, dermal dendritic cells, and 
perifollicular cells in formalin-fixed normal skin, and on proliferating endothelial cells and stromal spindle-shaped cells in Kaposi's sarcoma," Archives of Dermatology, vol. 127, no. 4, pp. 523-529, 1991.

[31] S. W. Weiss and B. J. Nickoloff, "CD-34 is expressed by a distinctive cell population in peripheral nerve, nerve sheath tumors, and related lesions," American Journal of Surgical Patho$\log y$, vol. 17, no. 10, pp. 1039-1045, 1993.

[32] B. R. De Young and M. R. Wick, "CD31: an immunohistochemical marker for endothelial cell differentiation in human neoplasms," Applied Immunohistochemistry, vol. 1, p. 97, 1993.

[33] G. S. Wood, J. H. Beckstead, R. R. Turner et al., "Malignant Fibrohistiocytoma tumours resemble fibroblasts," American Journal of Surgical Pathology, vol. 10, p. 323, 1986.

[34] I. Damjanov, "Antibodies to intermediate filaments and histogenesis," Laboratory Investigation, vol. 47, no. 3, pp. 215-217, 1982.

[35] M. B. Wilson, W. Stanly, and D. Sens, "Infentile fibrosarcoma a misnomer," Pediatric Pathology, vol. 10, p. 901, 1990.

[36] A. Beham, C. Schmid, S. Hodl, and C. D. M. Fletcher, "Spindle cell and pleomorphic lipoma: an immunohistochemical study and histogenetic analysis," Journal of Pathology, vol. 158, no. 3, pp. 219-222, 1989.

[37] S. Persson and L. G. Kinblom, "Metastasing gastric epotheloid leomyosarcoma in young individuals with long term survival," Cancer, vol. 70, p. 721, 1992.

[38] Y. Tatemoto, T. Tanaka, Y. Okada, and M. Mori, "Adenomatoid odontogenic tumour: co-expression of keratin and vimentin," Virchows Archiv, vol. 413, no. 4, pp. 341-347, 1988.

[39] H. Takahashi, S. Fujita, and H. Okabe, "Immunohistochemical investigation in odontogenic myxoma," Journal of Oral Pathology and Medicine, vol. 20, no. 3, pp. 114-119, 1991.

[40] M. Miyauchi, T. Takata, I. Ogawa et al., "Immunohistochemical observations on a possible ameloblastic fibro-odontoma," Journal of Oral Pathology and Medicine, vol. 25, no. 2, pp. 93-96, 1996.

[41] P. A. Coulombe and M. B. Omary, “'Hard' and 'soft' principles defining the structure, function and regulation of keratin intermediate filaments," Current Opinion in Cell Biology, vol. 14, no. 1, pp. 110-122, 2002.

[42] J. P. Ouhayoun, F. Gosselin, N. Forest, S. Winter, and W. W. Franke, "Cytokeratin patterns of human oral epithelia: differences in cytokeratin synthesis in gingival epithelium and the adjacent alveolar mucosa," Differentiation, vol. 30, no. 2, pp.123129, 1985.

[43] H. Clausen, D. Moe, K. Buschard, and E. Dabelsteen, "Keratin proteins in human oral mucosa," Journal of Oral Pathology, vol. 15, no. 1, pp. 36-42, 1986.

[44] K. Heikinheimo, M. Hormia, G. Stenman, I. Virtanen, and R. P. Happonen, "Patterns of expression of intermediate filaments in ameloblastoma and human fetal tooth germ," Journal of Oral Pathology and Medicine, vol. 18, no. 5, pp. 264-273, 1989.

[45] C. H. Siar and K. H. Ng, "Patterns of expression of intermediate filaments and S-100 protein in desmoplastic ameloblastoma," The Journal of Nihon University School of Dentistry, vol. 35, no. 2, pp. 104-108, 1993.

[46] Y. Tatemoto, Y. Okada, and M. Mori, "Squamous odontogenic tumor: immunohistochemical identification of keratins," Oral Surgery Oral Medicine and Oral Pathology, vol. 67, no. 1, pp. 6367, 1989.

[47] Y. Tatemoto, T. Tanaka, Y. Okada, and M. Mori, "Adenomatoid odontogenic tumour: co-expression of keratin and vimentin," Virchows Archiv, vol. 413, no. 4, pp. 341-347, 1988.
[48] T. Takata, M. Zhao, H. Nikai, T. Uchida, and T. Wang, "Ghost cells in calcifying odontogenic cyst express enamel-related proteins," Histochemical Journal, vol. 32, no. 4, pp. 223-229, 2000. 


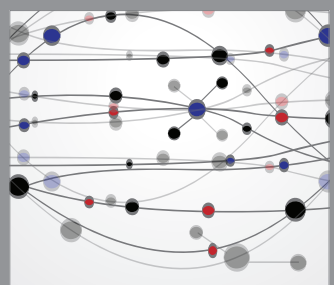

The Scientific World Journal
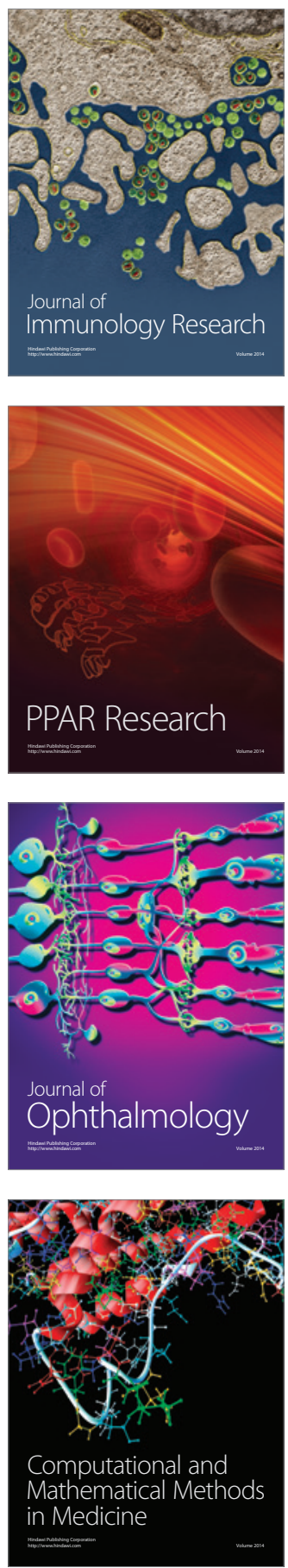

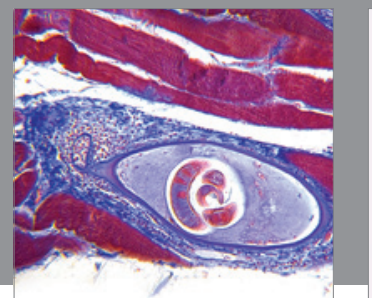

Gastroenterology

Research and Practice
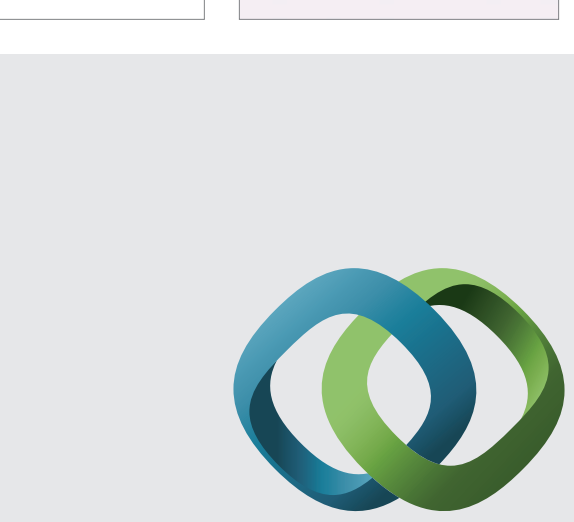

\section{Hindawi}

Submit your manuscripts at

http://www.hindawi.com
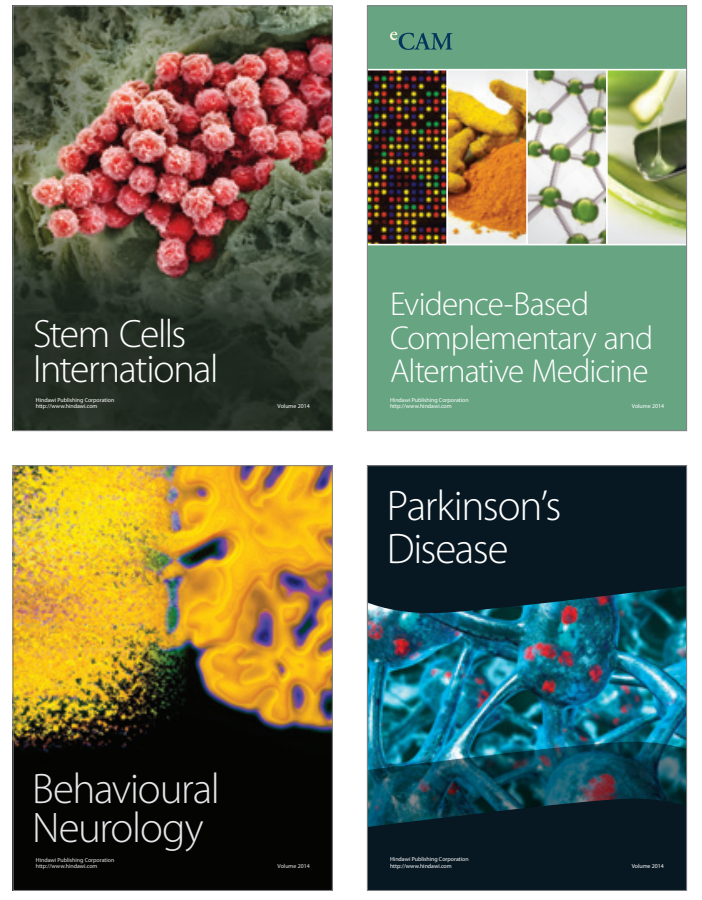
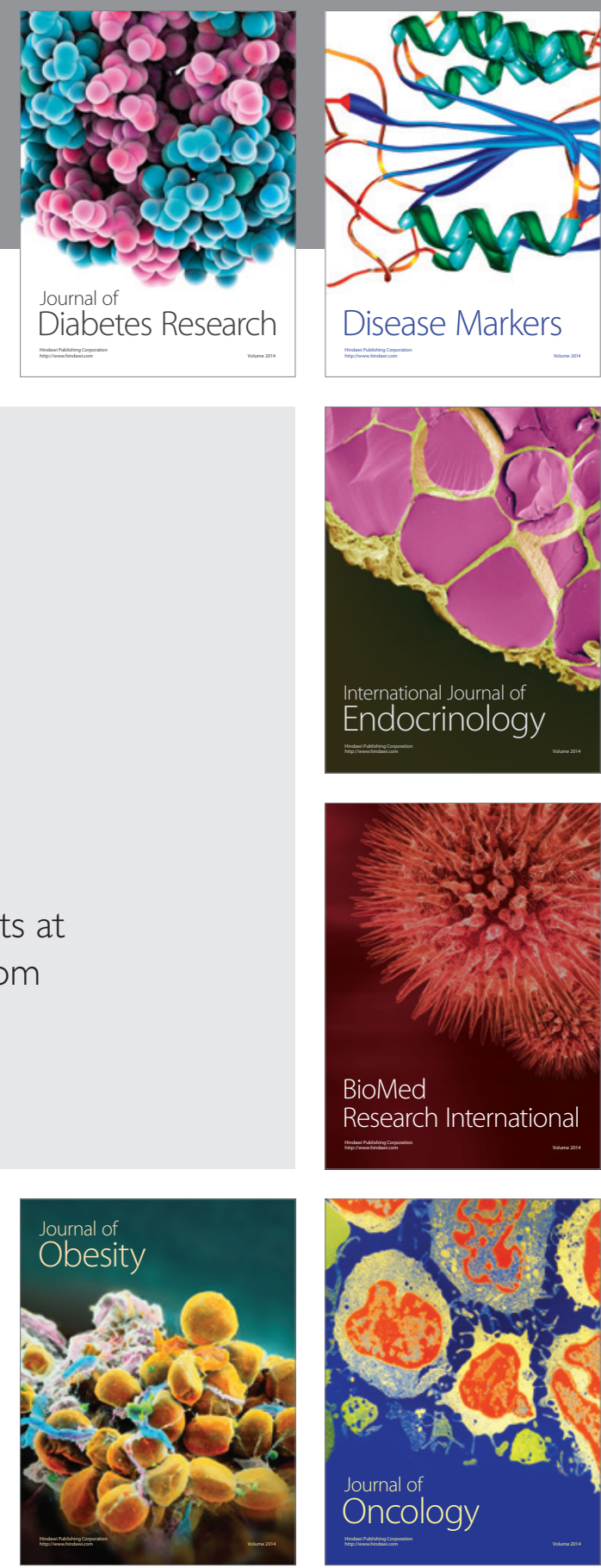

Disease Markers
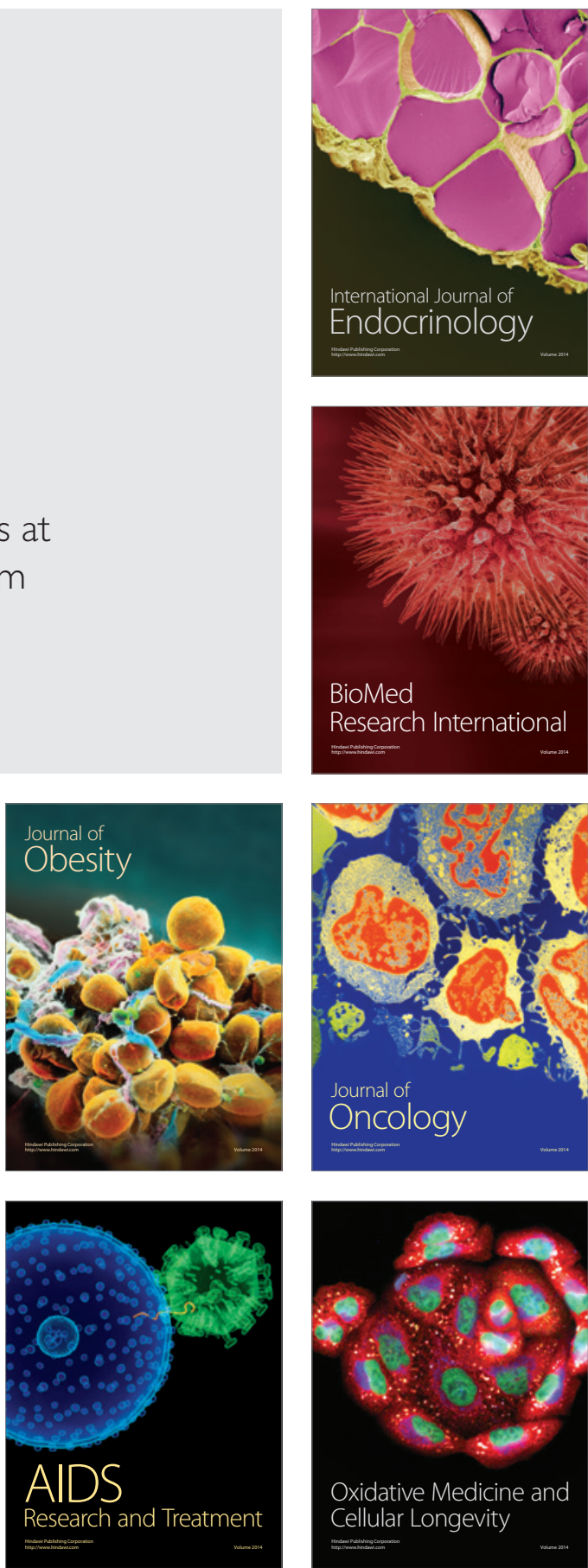